\title{
Paternal DNA strands segregate to both trophectoderm and inner cell mass of the developing mouse embryo
}

\author{
Kenichi Ito, James D. McGhee, and Gilbert A. Schultz \\ Department of Medical Biochemistry, University of Calgary, Calgary, Alberta T2N 4N1 Canada
}

The localization of sperm DNA strands was examined in preimplantation mouse embryos. Male mice were treated with bromodeoxyuridine (BrdU) to label germ-cell-line DNA and were then mated with unlabeled females. Sperm DNA strands in early embryos derived from these matings could be detected by means of a fluorescent antibody specific to BrdU. The position and number of fluorescent spots detected in the developing embryos are consistent with a model in which paternal DNA strands segregate at random into both the trophectoderm and the inner cell mass. Although we could not follow the segregation of individual paternal chromosomes, we could detect no overall segregation pattern of the sperm DNA strands that could be obviously related to chromosome imprinting.

[Key Words: Development; chromosome imprinting; mouse embryo; bromodeoxyuridine; sperm DNA]

Received April 20, 1988; revised version accepted June 13, 1988.

It is now well established that mouse development requires the participation of both a paternal and a maternal genome. Evidence comes from both nuclear transplantation experiments (McGrath and Solter 1984; Surani et al. 1984, 1986) and from classical genetics (Cattanach and Kirk 1985). The question of current interest is the molecular nature of this 'chromosome imprinting.'

Several recent studies have used transgenic mice to show that the methylation pattern of the transgene can depend on whether the DNA came from the mother or from the father (Reik et al. 1987; Sapienza et al. 1987; Swain et al. 1987). In one case (Swain et al. 1987), these methylation differences correlated exactly with tissuespecific expression of the transgene. Although parentspecific methylation differences currently seem the most likely explanation for chromosome imprinting, this may not be the only mechanism operating. In this paper, we consider a different explanation for chromosome imprinting in the mouse, namely whether the original DNA strands of the sperm genome show a specific pattern of segregation during development.

It is important to distinguish between chromosome imprinting mechanisms in which the imprinting information can propagate from those in which the imprinting information does not necessarily propagate. Methylation patterns of the kind reported recently (Reik et al. 1987; Sapienza et al. 1987; Swain et al. 1987) are in principle completely self-propagating. In contrast, strand segregation mechanisms could be completely non-propagating. That is, we are investigating something chemically unique about the particular DNA strands; this could be a stably bound protein, a meta-stable chromatin configuration, or even a methylation pattern that is not copied. Since transcription of the zygotic genome begins at the two-cell stage in mouse embryogenesis (for review, see Schultz 1986), such patterned segregation need only be temporary but could still have a major effect on subsequent development.

The possibility of non-random segregation of DNA strands as a potential biological control mechanism has been considered several times in the past. In the fission yeast Saccharomyces pombe, Klar (1987) has demonstrated that a specific DNA strand segregation pattern controls which cell in a cell lineage will change mating type. On the other hand, during development of the nematode Caenorhabditis elegans, segregation of parental DNA appears to be essentially random (Ito and McGhee 1987). During mouse development, it is not known how gamete DNA segregates and it is this problem that we address here. We look for evidence that sperm DNA strands either cosegregate completely or, a less extreme result, that sperm DNA is differentially distributed between the two major lineages of the early mouse embryo, the trophectoderm and the inner cell mass.

\section{Results}

\section{Mouse sperm DNA can be labeled with BrdU}

The overall experimental plan is shown in Figure 1 and is based on our previous experiments with C. elegans (Ito and McGhee 1987). The aim is to label sperm DNA 
Ito et al.

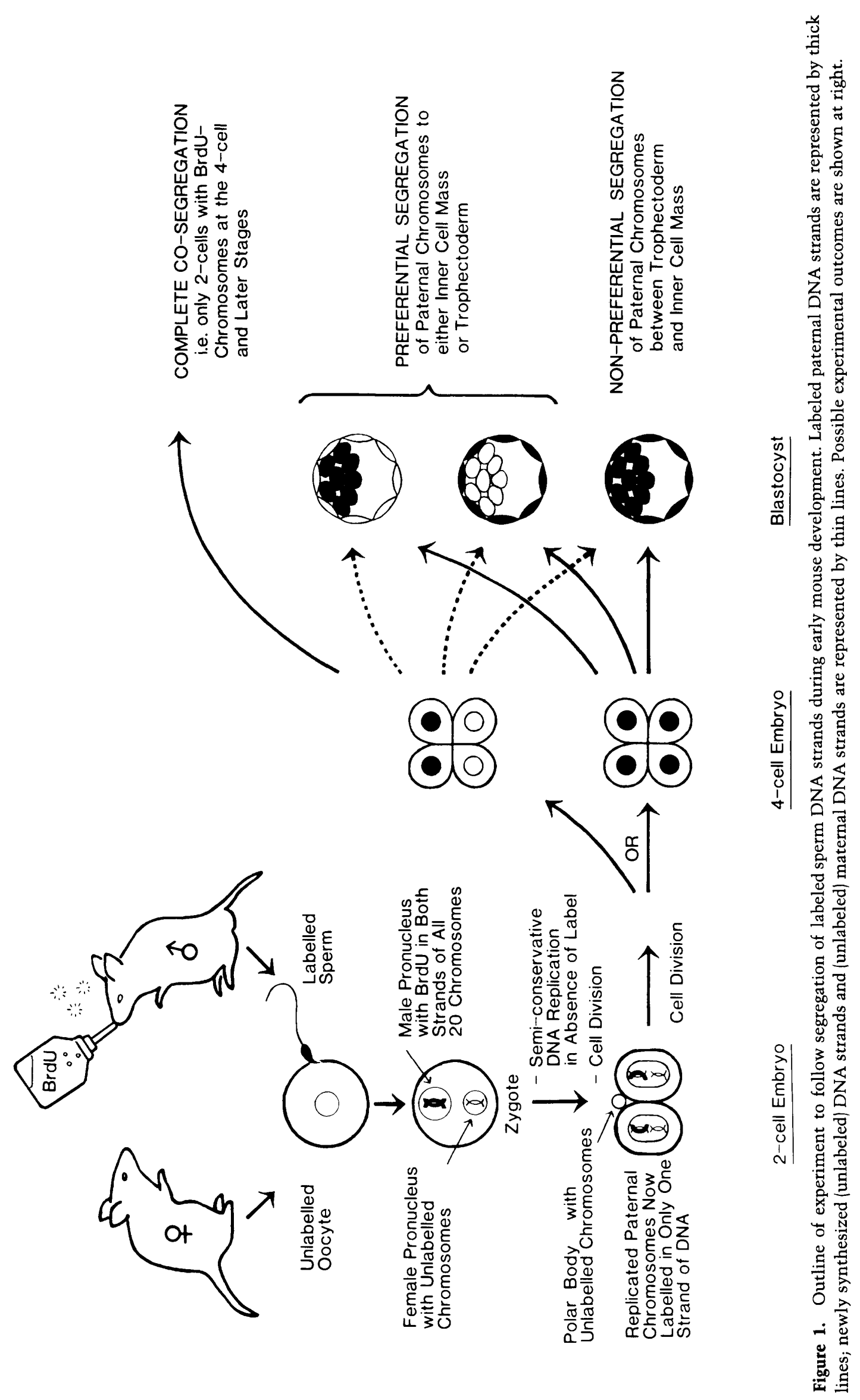


with the deoxynucleoside analog bromodeoxyuridine (BrdU) and to detect the BrdU in embryos of the next generation by immunofluorescence using a monoclonal antibody. To label sperm DNA, male mice were supplied with BrdU $(0.5 \mathrm{mg} / \mathrm{ml})$ in their drinking water for 1-2 months. Treated males were then mated with untreated females and embryos were collected 0.5-3.5 days later by flushing the oviduct or uterus. All matings were natural because superovulation has been reported to increase the rate of sister chromatid exchange (Elbling and Colot 1985a). Exactly as predicted from the normal sperm cycle (Monesi 1962), the label could be detected with the anti-BrdU antibody in some of the embryos derived from mating with males that had been exposed to BrdU for 35 days. Males that had been exposed to BrdU for 35-38 days and that had then been mated once in order to remove unlabeled sperm, subsequently produced essentially $100 \%$ labeled embryos.

To show the sensitivity and specificity of the BrdU labeling, two-cell embryos produced by treated male mice were cultured in vitro in the presence of colcemid to condense the chromosomes. Figure 2a shows a typical metaphase spread labeled with the DNA-specific fluorescent dye diamidinophenylindole (DAPI) to show both the maternal and the paternal chromosome sets. In Figure $2 b$, the same spread has been treated with the anti-BrdU antibody and then with a rhodamine-labeled secondary antibody. It is clear that the BrdU label can be detected in roughly half of the 40 chromosomes, as expected if all sperm chromosomes are labeled and if the label has not been randomized. When individual chromosomes are well spread, it can be seen that label is present in only one of the two chromatids and moreover appears to be uniform throughout the chromatid length. This is as expected for two-cell embryos (see Fig. 1) and is a necessary condition for a strand segregation experiment.

Figure 3 provides a further demonstration of the specificity of our labeling procedure. A labeled two-cell embryo was gently squashed and then stained with DAPI (Fig. 3a) and with the anti-BrdU antibody (Fig. 3b). As expected from the semi-conservative synthesis of DNA (see Fig. 1), both nuclei of the embryo stain with the antibody but there is no detectable staining of the polar body (Fig. 3b, arrow).

Although antibody staining within these early nuclei can appear punctate, we do not find regions of the nuclei that remain completely unlabeled. That is, we do not confirm the claim that paternal DNA is localized in interphase nuclei of early mouse embryos (Odartchenko and Keneklis 1973) and we suggest that these results could have been due to only partial labeling of the sperm genome.

Sperm DNA strands do not cosegregate at the four-cell stage of the embryo

As shown in Figure 1, the four-cell stage of the embryo is the first point at which cosegregation of sperm DNA strands could possibly be observed. In the extreme case, if paternal DNA strands were to cosegregate completely, only two of the four nuclei would be labeled. Figure 4 shows clearly that paternal DNA strands do not cosegregate completely: All four nuclei of four-cell embryos (seen by DAPI staining in Fig. 4a) are also labeled with BrdU, with roughly equal intensity (Fig. $4 \mathrm{~b}$ ). The pictures demonstrate again the high specificity of the labeling procedure, because the polar bodies (arrows) do not stain.

\section{Distribution of the sperm DNA strands between the inner cell mass and the trophectoderm of the developing blastocyst}

The allocation of cells to the two principal lineages of the embryo, the trophectoderm and the inner cell mass (ICM), is thought to be complete at the 32-cell stage (for review, see Pedersen 1986). Because the paternal genome sustains trophectoderm development to a greater extent than it does the development of the ICM (Surani 1986), we examined how the paternal DNA strands distribute themselves between these two lineages.

Figure 5 shows an example of an expanded blastocyst ( $\sim 60$ cells), stained with both DAPI and with the antiBrdU antibody. The pink spots (i.e., the paternal DNA strands) are present in cell nuclei of both the trophectoderm and the ICM. The spot number is $\sim 40$, as expected if all sperm DNA strands are being detected and if sister chromatid exchange does not occur at a high level. (The actual counts ranged between 30 and 60, depending on our counting convention. This variation was undoubtedly due to the difficulty in defining the fluorescence from individual noncondensed chromosomes.) Thus, we can conclude that paternal DNA strands do not completely segregate either to the trophectoderm or to the ICM.

Quantitative analysis of the spot distribution between the trophectoderm and the ICM is difficult in the blastocyst, because of both optical problems and the difficulty of assigning a number of cells to one lineage or the other. Thus, we looked for labeled sperm DNA in ICMs isolated by immunosurgery. Figure 6 shows two separate ICMs. The ICM nuclei clearly receive paternal DNA strands and we now show that the spot number is consistent with random segregation.

To obtain an objective estimate of the proportion of sperm DNA strands that distribute into the ICM, we confined our analysis to only the best embryo preparations and made an effort to count each and every discrete spot as a separate strand. In many cases, neighboring spots are likely to be part of the same incompletely condensed chromosome and thus the spot number must be an overestimate of the actual number of labeled strands. However, as long as spots in the ICMs and spots in total blastocysts are counted by the same convention, the ratio of the two counts should still be a valid and objective measure of the strand distribution. With this convention, we counted an average of 27 spots $( \pm$ S.D. $=5$; 9 embryos) in isolated ICMs and an average of 59 spots 

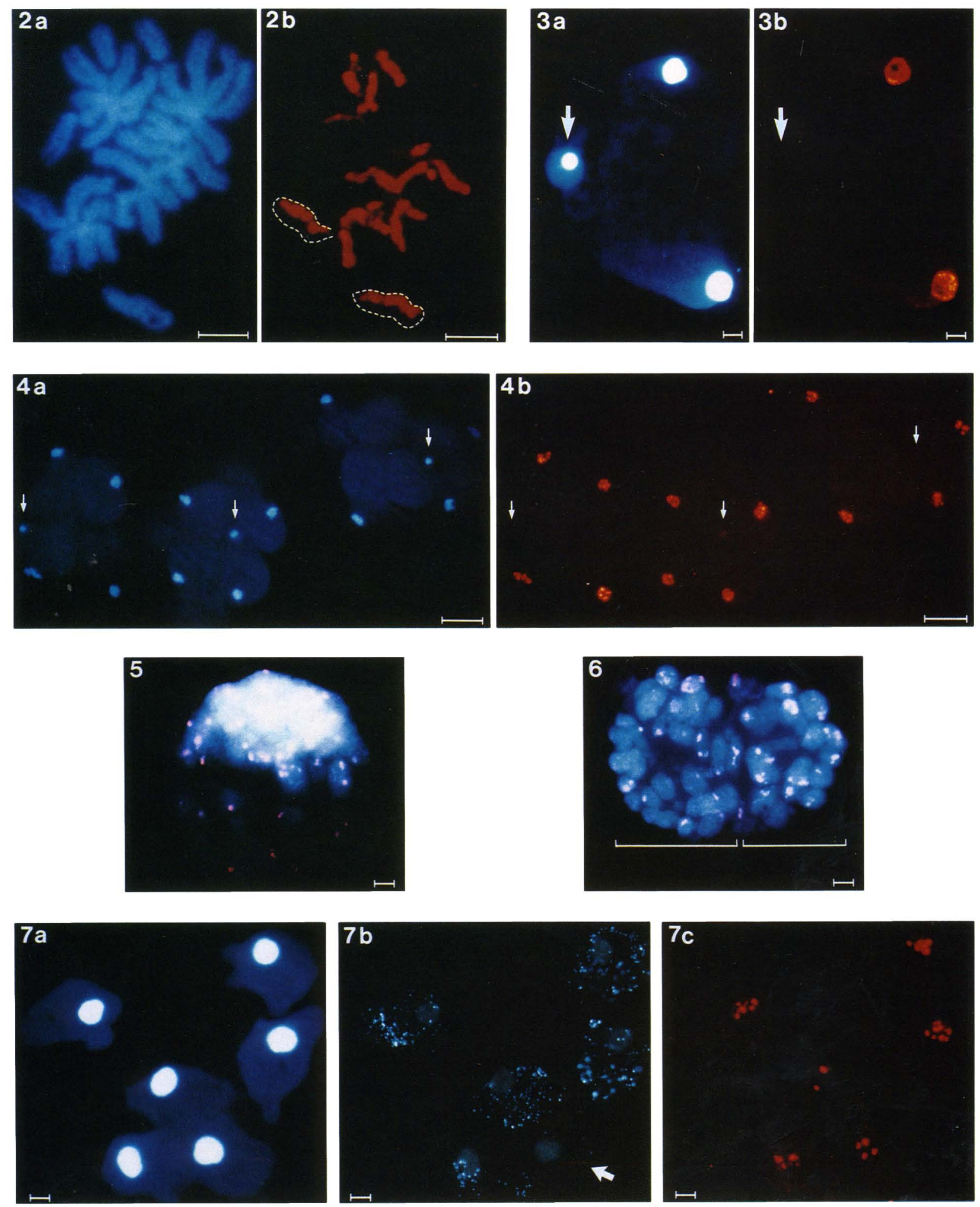

Figures 2-7. (See facing page for legends.) 
( \pm S.D. $=11 ; 13$ embryos $)$ in total blastocysts. That is, we estimate that $0.46( \pm$ S.D. $=0.12)$ of paternal DNA strands segregate into the ICM. If strand segregation is random, then the expected distribution should simply be the fraction of cells in a 32-cell embryo that are in the ICM. From the extensive data of Fleming (1987), this cell fraction is $0.40 \pm 0.06$, in satisfactory agreement with our observed strand distribution.

We also looked for nonrandom strand segregation at the earliest stages of formation of the ICM, when the embryo has a total of 10-16 cells. At this point, the experiment might be expected to be maximally sensitive to asymmetries. To distinguish outside from inside cells, the outside cells were labeled using fluorescent latex beads (Fleming and George 1987). The embryos were then partially disaggregated and the distribution of sperm DNA was measured. An example is shown in Figure 7. By comparing the DAPI stain (Fig. 7a) with the latex bead distribution (Fig. $7 \mathrm{~b}$ ) and with the anti-BrdU DNA stain (Fig. 7c), it is clear that both outside and inside cells receive paternal DNA strands. Among ten preparations of embryos at the 10-16-cell stage and in which we could unambiguously assign one or two cells as inside, the number of spots in the inside cells varied between two and six, a reasonable expectation for random segregation. At this early stage of development, not a single cell nucleus (inside or outside) was observed that did not contain label. Thus, we conclude that cell allocation during the process of ICM formation occurs without regard to the overall distribution of the original sperm DNA strands.

Because of technical complexities, we were unable to follow labeled sperm DNA strands later in development, in post-implantation embryos.

\section{Control experiments}

Viable offspring are produced by the BrdU-containing sperm To rule out developmental abnormalities induced by the BrdU-labeling procedure itself, several females were mated to males that had been shown a few days earlier to produce labeled embryos. The pregnancies were allowed to go to term. Of ten such matings analyzed, all offspring were normal (and fertile) and the average litter size was $11.6( \pm$ S.D. $=1.5)$, which is exactly that expected for CD1 mice (11.6; Hill 1983). We also verified, in 19 other matings with BrdU-treated males, that the mean number of implantation sites at day 6.5 of pregnancy was $12.9( \pm$ S.D. $=1.6)$, close to the normal number of 12.6 (Hill 1983). Thus, there is no evidence that the BrdU-labeling of the sperm leads either to abnormal offspring or to an abnormal number of embryos lost during development.

Strand segregation pattern is unlikely to be influenced by sister chromatid exchange In our previous work with C. elegans (Ito and McGhee 1987), because the labeled spots corresponding to sperm DNA strands were so discrete and because the total spot number agreed so closely with the total number of sperm strands, any effect of sister chromatid exchange could be discounted. This is not so easily done in the present experiment, where the total number of sperm strands is much higher and where counting the unavoidably diffuse spots is expected to overestimate the strand number. However, simple calculations readily show that sister chromatid exchange is unlikely to be the cause of the apparently random strand segregation that we observe.

Elbling and Colot (1985b) cultured early mouse embryos in BrdU and counted about 2.6 sister chromatid

Figure 2. Mouse sperm DNA can be labeled with BrdU. Two-cell embryos produced by BrdU-treated male mice were cultured in vitro in the presence of colcemid to condense the chromosomes. $(a \mid$ A metaphase spread prepared from one blastomere was stained with DAPI. $(b)$ Original sperm DNA in the same preparation was detected by the anti-BrdU antibody followed by a rhodamine-labeled goat anti-mouse secondary antibody. The dashed lines represent the outlines of the DAPI-stained image for two selected chromosomes and show that only one of the two chromatids contains BrdU. Bar $=10 \mu \mathrm{m}$.

Figure 3. Distribution of labeled sperm DNA in a two-cell embryo. (a) DAPI staining, to show chromosomal DNA from both nuclei and the polar body (arrow). (b) BrdU-containing DNA detected by the anti-BrdU antibody. The arrow points to the unlabeled polar body. Bar $=10 \mu \mathrm{m}$.

Figure 4. Distribution of paternal DNA strands within four-cell embryos. Three four-cell embryos are shown. $(a)$ Total nuclear DNA stained with DAPI. $(b)$ BrdU-containing DNA detected by the anti-BrdU antibody. Bar $=50 \mu \mathrm{m}$. Arrows point to polar bodies.

Figure 5. Sperm DNA strands (pink spots) detected within a DAPI-stained blastocyst stage embryo. Bar $=10 \mu \mathrm{m}$.

Figure 6. Sperm DNA strands (pink spots) detected within the embryonic inner cell mass. The figure shows two ICMs that had been isolated by immunosurgery and then stained with DAPI and with the anti-BrdU antibody. Bar $=10 \mu \mathrm{m}$.

Figure 7. Sperm DNA strands segregate to both inside and outside cells of the morula. Six cells of a selected 15-cell embryo are shown: (a) Labeled with DAPI to show nuclear DNA. (b) Treated with fluorescein-conjugated latex beads to distinguish the five labeled outside cells from the one unlabeled inside cell (arrow). (c) Labeled with the anti-BrdU antibody. Bar $=10 \mu \mathrm{m}$. 
exchange events per metaphase, i.e., a sister chromatid exchange rate of about $6.6 \%$ per strand per cell division. Ignoring the possibility that this exchange rate measured in cultured embryos could well be higher than in the unperturbed embryo, we can use this value to calculate the consequences of the following model. Suppose that paternal DNA strands were programmed to segregate completely into the embryonic trophectoderm but that sister chromatid exchange occurred at the above rate whereupon one of the exchanged product chromosomes (e.g., the product containing the unlabeled centromere) now segregated at random. Three arguments show that this model cannot explain the apparent random segregation that we observe.

1. In the five divisions between the 2-cell stage and the 64-cell blastocyst, the assumed exchange would increase the spot number by a factor of $(1.066)^{5}$, i.e., an extra 15 spots would be generated of which about 6 would then be expected to end up in the ICM. We actually observe over four times this number of spots in the ICM.

2. An even stronger argument against the model can be made using our data on the presence of label in the inside cells of 10-16-cell embryos (see Fig. 7). During the three divisions between a 2-cell and a 16-cell embryo, our assumed rate of sister chromatid exchange would give rise to an extra 8 spots [i.e., $40(1.066)^{3}-$ 40]. If these extra spots segregated at random, the probability that any particular ICM nucleus would contain no label would be roughly $60 \%$. On the contrary, we observed that all inside cells examined ( 35 of 35) were labeled.

3. As seen in Figure 7c, nuclei of inside cells are labeled with roughly the same intensity as the nuclei of outside cells and spot size in the two cell classes was generally indistinguishable.

Thus, we conclude that sister chromatid exchange cannot be the reason that sperm DNA strands appear to segregate randomly between the trophectoderm and the ICM.

\section{Discussion}

We have shown that mouse sperm DNA can be easily and efficiently labeled with BrdU and that this label can be detected in early embryos of the next generation. This method should be useful generally for the study of DNA synthesis during spermatogenesis and for the study of mutagenic effects that show up as chromosome abnormalities in early embryos.

Using the BrdU labeling method, we have been able to follow the fate of paternal sperm DNA strands during the first 5-6 cell divisions of embryogenesis. We can rule out the most extreme model for paternal DNA segregation, namely that paternal DNA strands all rigidly segregate together. This model would predict only two labeled cells in the embryo at any time during embryogenesis. This is clearly not the observed result.
We can also rule out a model in which sperm DNA is segregated completely, either to the embryonic trophectoderm or to the ICM. Contrary to this prediction, we find a roughly equal distribution between the two lineages. Since in diandric embryos, paternal nuclei alone give rise to extensive development of the trophectoderm but poor development of the embryo proper (Surani 1986), this is an important model to reject.

Overall, we could detect no obvious pattern of chromatid segregation during early development and our results are consistent with random segregation, as we have shown earlier with the nematode C. elegans (Ito and McGhee 1987). However, by the nature of the present experimental system, it is difficult to be more quantitative and definitive. In particular, we certainly cannot reject a model in which a particular chromosome from the father is always segregated into a particular lineage of the embryo. This is an important consideration because paternal chromosome imprinting is associated with only some of the chromosomes (Cattanach and Kirk 1985; Surani 1986). Another model that we cannot evaluate is whether paternal DNA strands segregate in some strictly patterned manner during the first few cell divisions but segregate at random thereafter. Since the mouse genome is expressed so early, such a transient segregation could have profound consequences on subsequent development. Whether it actually occurs is, of course, another matter.

The most attractive current model to explain chromosome imprinting is differential methylation patterns induced by passage through the male or the female germcell line (Reik et al. 1987; Sapienza et al. 1987; Swain et al. 1987). Our results can say nothing about this model and it is important to distinguish between the different kinds of imprinting mechanisms being investigated. Methylation patterns are in principle self-propagating; it could be irrelevant where the original sperm DNA ends up, as long as the methylation pattern is passed on. In contrast, the present experiments investigate the possibility of non-propagating information that remains uniquely associated with the original sperm DNA strand. In this case, segregation patterns could be crucial. However, we find no evidence that sperm DNA segregation is anything but random.

\section{Materials and methods}

\section{Labeling sperm DNA strands}

The cycle time to produce spermatozoa from mitotic spermatogenic cells in mice is $32-34$ days (Monesi 1962). Male CD1 mice (Charles River Breeding Laboratories) 12-16 weeks of age were supplied with drinking water containing BrdU at a concentration of $0.5 \mathrm{mg} / \mathrm{ml}$ continuously for 35 days. The water bottles were covered with aluminum foil to protect the BrdU solution from light and, as a rule, water containing BrdU was changed at two-week intervals. Previous reports (Phupanich and Levin 1985) have indicated that BrdU is stable in water for up to one month. HPLC analysis (kindly done by Dr. Richard Pon, University of Calgary) on water used to treat males for two weeks indicated that, in even the most contaminated bottles, greater than $75 \%$ (and usually close to $100 \%$ ) of the original 
BrdU concentration was still present. Male CDl mice weigh $\sim 35 \mathrm{~g}$ and drink $\sim 6.0 \mathrm{ml}$ of water per day (Hill 1983); thus, the average dosage of BrdU was $86 \mathrm{mg}$ per kilogram body weight per day. This level is below the dose $(300-500 \mathrm{mg} / \mathrm{kg} / \mathrm{day})$ reported to be toxic in rodents or to induce neural tube defects in pregnant mice (Banningan 1985; Phuphanich and Levin 1985). In our initial experiments, the dose of BrdU used was $1 \mathrm{mg} / \mathrm{ml}$ but 2 of 12 mice developed lesions in one eye after three weeks of treatment. These lesions disappeared when the mice were returned to normal drinking water. The lower concentration of $0.5 \mathrm{mg} / \mathrm{ml}$ produced no obvious side effects and was used for all the experiments reported in the current paper.

After the BrdU treatment (35 days or longer), males were used for mating only during the next three week period in order to avoid appearance of unlabeled sperm from successive spermatogenic cycles. The average number of matings per labeled male was 2.8 .

\section{Mating and recovery of preimplantation embryos}

Females were caged with BrdU-treated males and the appearance of a copulation plug the next morning was used to infer that fertilization had occurred approximately $12 \mathrm{hr}$ earlier. Embryos were recovered by flushing oviducts with $\mathrm{M} 2$ medium (Hogan et al. 1986) at day 1.5 (after fertilization) for 2-cell embryos, day 2.0 for 4 cell embryos, and day 2.5 for uncompacted 8-cell embryos. Early morulae (10-16 cells) were recovered from mated females at $\sim 3.0$ days and blastocysts $(\sim 64$ cells $)$ were flushed from uteri at 3.5-4.0 days.

\section{Preparation of chromosome spreads}

Two-cell embryos were incubated in M16 medium (Hogan et al. 1986) containing $0.1 \mu \mathrm{g} / \mathrm{ml}$ colcemid (GIBCO, catalog no. $120-5210)$ at $37^{\circ} \mathrm{C}$ overnight. After removal of zonae pellucidae in acidic Tyrode's solution (Hogan et al. 1986), the embryos were incubated in a drop of cold $0.9 \%$ sodium citrate solution (Dyban 1983) on a subbed slide (Gall and Pardue 1971) for 30 min at $4^{\circ} \mathrm{C}$. The embryos were then gently disrupted by addition of a drop of $1 \%$ Nonidet P. 40 (Sigma) in $0.9 \%$ sodium citrate and air-dried. The slides were fixed in $75 \%$ ethanol for 30 min at room temperature and air-dried. Unfortunately, the acetic acid treatment that is usual for chromosome spreads had to be avoided because it interfered with subsequent antibody staining.

\section{Preparation of embryo samples}

Two- and four-cell embryos were incubated in M16 medium containing $0.1 \mu \mathrm{g} / \mathrm{ml}$ colcemid at $37^{\circ} \mathrm{C}$ overnight in order to concentrate the chromosomes into a small area. After removal of zonae pellucidae in acidic Tyrode's solution, two-cell, fourcell, and blastocyst stage embryos were gently squashed under a siliconized coverslip on a subbed slide and the slide was frozen on crushed dry ice. Immediately after removal of the coverslip, the slide was fixed in $75 \%$ ethanol for $30 \mathrm{~min}$ at room temperature and air-dried.

\section{Detection of BrdU-containing DNA}

Detection of BrdU-containing DNA was carried out as described by Ito and McGhee (1987). Briefly, after acid denaturation, slides were neutralized and incubated with a mouse monoclonal anti-BrdU antibody (Becton-Dickinson, catalog no. 7580) followed by a rhodamine-labeled goat anti-mouse secondary antibody (Cooper Biomedical, catalog no. 2211-023).
Preparations were observed with a Zeiss IM35 inverted microscope equipped with epifluorescence optics and photographed using Ektachrome 400 color slide film. When necessary, photographs were taken in several different focal planes. Two types of control experiments verified the specificity of the anti-BrdU antibody: (1) Preimplantation embryos derived from matings between untreated males and females never exhibited nuclear fluorescence when treated as above. (2) In testis cell preparations from treated males, the antibody reaction with BrdU-containing DNA and the resulting fluorescence were eliminated by competition with excess free BrdU.

\section{Isolation of ICM}

ICMs from expanded blastocysts were isolated by treatment with rabbit anti-mouse serum and guinea pig complement, essentially as described by Handyside and Barton (1977) and Miller and Schultz (1985).

Labeling outside cells of compacted morulae with fluorescent latex beads

After overnight incubation of compacted monulae in M16 medium containing $0.1 \mu \mathrm{g} / \mathrm{ml}$ colcemid at $37^{\circ} \mathrm{C}$, zonae pellucidae were removed in acidic Tyrode's solution and outside cells were labeled by internalization of fluorescent latex microparticles (Polysciences $0.21-\mu \mathrm{m}$ diameter particles, catalog no. 9834) as described by Fleming and George (1987). The embryos were partially disaggregated by treatment with calcium-free medium and disrupted by repeated up and down movement of a drawn-out capillary pipette. The cells were then gently squashed under a siliconized coverslip on a subbed slide and fixed as described above.

\section{Acknowledgments}

This work was supported by Operating Grants from the Medical Research Council of Canada to G.A.S. and J.D.M. and by an Establishment Grant from the Alberta Heritage Foundation of Medical Research (AHFMR) to J.D.M. K.I. is an AHFMR Doctoral Student and J.D.M. is an AHFMR Medical Scientist. We should like to thank Ms. Tiziana Cyron for preparation of the manuscript.

\section{References}

Bannigan, J.G. 1985. Effects of 5'-bromodeoxyuridine on fusion of the cranial neural folds in the mouse embryo. Teratology 32: 229-239.

Cattanach, B.M. and M. Kirk. 1985. Differential activity of maternally and paternally derived chromosome regions in mice. Nature 315: 496-498.

Dyban, A.P. 1983. An improved method for chromosome preparations from preimplantation mammalian embryos, oocytes or isolated blastomeres. Stain Technol. 58: 69-72.

Elbling, L. and M. Colot. 1985a. Abnormal development and transport and increased sister-chromatid exchange in preimplantation embryos following superovulation in mice. Mutat. Res. 147: 189-195.

- 1985b. A method for analysing sister-chromatid exchange in mouse preimplantation embryos. Mutat. Res. 147: $23-28$.

Fleming, T.P. 1987. A quantitative analysis of cell allocation to trophectoderm and inner cell mass in the mouse blastocyst. Dev. Biol. 119: 520-531.

Fleming, T.P. and M.A. George. 1987. Fluorescent latex micro- 
particles: a non-invasive short-term cell lineage marker suitable for use in the mouse early embryo. Wilhelm Roux's Arch. Dev. Biol. 196: 1-11.

Gall, J.G. and M.L. Pardue. 1971. Nucleic acid hybridization in cytological preparations. Methods Enzymol. 21: 470-480.

Handyside, A.H. and S.C. Barton. 1977. Evaluation of the technique of immunosurgery for isolation of inner cell masses from mouse blastocysts. J. Embryol. Exp. Morph. 37: 217226.

Hill, B.F. 1983. The CD-1 mouse, history, and utilization. In Charles River Digest vol. 22, pp. 1-4. Charles River Breeding Laboratories, Wilmington, Massachusetts.

Hogan, B., F. Costantini, and E. Lacy. 1986. Manipulating the mouse embryo: A laboratory manual. Cold Spring Harbor Laboratory, Cold Spring Harbor, New York.

Ito, K. and J.D. McGhee. 1987. Parental DNA strands segregate randomly during embryonic development of Caenorhabditis elegans. Cell 49: 329-336.

Klar, A.J.S. 1987. Differentiated parental DNA strands confer developmental asymmetry on daughter cells in fission yeast. Nature 326: 466-470.

McGrath, J. and D. Solter. 1984. Completion of mouse embryogenesis requires both the maternal and paternal genomes. Cell 37: 179-183.

Miller, J.G.O. and G.A. Schultz. 1985. Amino acid transport in mouse blastocyst compartments. J. Embryol. Exp. Morph. 89: $149-158$.

Monesi, V. 1962. Autoradiographic study of DNA synthesis and the cell cycle in spermatogonia and spermatocytes of the mouse testis using tritiated thymidine. I. Cell Biol. 14: $1-18$.

Odartchenko, N. and T. Keneklis. 1973. Localization of paternal DNA in interphase nuclei of mouse eggs during early cleavage. Nature 241: 528-529.

Pedersen, R.A. 1986. Potency, lineage, and allocation in preimplantation mouse embryos. In Experimental approaches to mammalian embryonic development (ed. J. Rossant and R.A. Pedersen) pp. 3-33. Cambridge University Press, Cambridge.

Phuphanich, S. and V.A. Levin. 1985. Bioavailability of bromodeoxyuridine in dogs and toxicity in rats. Cancer Res. 45: $2387-2389$.

Reik, W., A. Collick, M.L. Norris, S.C. Barton, and M.A.H. Surani. 1987. Genomic imprinting determines methylation of parental alleles in transgenic mice. Nature 328: 248-251.

Sapienza, C., A.C. Peterson, J. Rossant, and R. Balling. 1987. Degree of methylation of transgenes is dependent on gamete of origin. Nature 328: 251-254.

Schultz, G.A. 1986. Molecular biology of the early mouse embryo. Biol. Bull. 171: 291-309.

Surani, M.A.H., S.C. Barton, and M.L. Norris. 1984. Development of reconstituted mouse eggs suggests imprinting of the genome during gametogenesis. Nature 308: 548-550.

1986. Nuclear transplantation in the mouse: heritable differences between parental genomes after activation of the embryonic genome. Cell 45: 127-136.

Surani, M.A.H. 1986. Evidences and consequences of differences between maternal and paternal genomes during embryogenesis in the mouse. In Experimental approaches to mammalian embryonic development led. J. Rossant and R.A. Pedersen/ pp. 401-435, Cambridge University Press, Cambridge.

Swain, J.L., T.A. Stewart, and P. Leder. 1987. Parental legacy determines methylation and expression of an autosomal transgene: a molecular mechanism for parental imprinting. Cell 50: 719-727. 


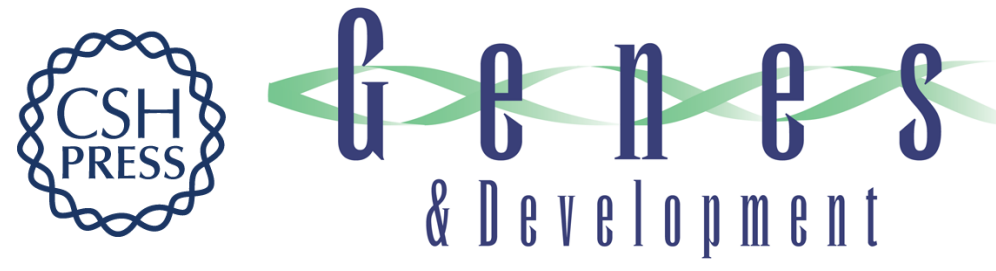

\section{Paternal DNA strands segregate to both trophectoderm and inner cell mass of the developing mouse embryo.}

K Ito, J D McGhee and G A Schultz

Genes Dev. 1988, 2:

Access the most recent version at doi:10.1101/gad.2.8.929

References This article cites 22 articles, 1 of which can be accessed free at: http://genesdev.cshlp.org/content/2/8/929.full.html\#ref-list-1

License

Email Alerting

Service

Receive free email alerts when new articles cite this article - sign up in the box at the top right corner of the article or click here.

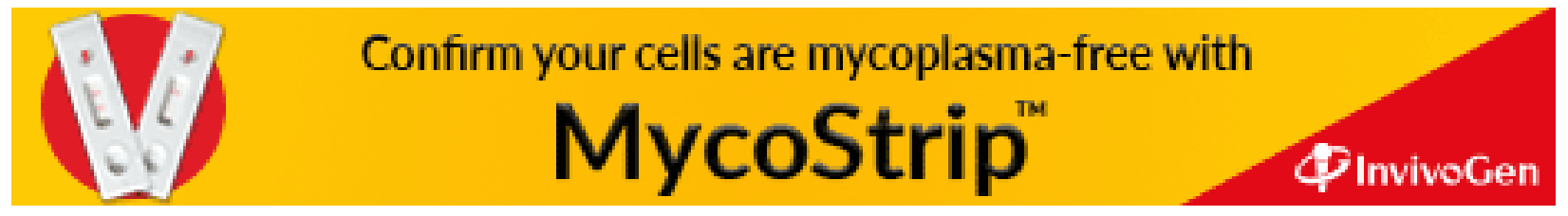

